\title{
Improving Accessibility for Students with Visual Disabilities in the Technology-Rich Classroom
}

Michael A. Taylor, Seton Hall University

ABSTRACT As higher education has increasingly embraced digital technologies, we have been too slow to acknowledge accessibility issues for students with visual disabilities. One of the earliest promises of information and communication technology was increased accessibility to content. In theory, digitized content should be as equally accessible as the printed word on a screen, a braille keyboard, or an audible voice on a speaker. In the majority of educational technology, this promise has gone unfulfilled, and faculty members are largely unaware of the myriad obstacles that students with visual disabilities confront while navigating the technology-rich classroom. The principles of Universal Design in Instruction (UDI) provide guidance for developing curriculum that maximizes accessibility and usability of course content for all learners, including those with disabilities. This article examines the development of political science courses through the lens of UDI.

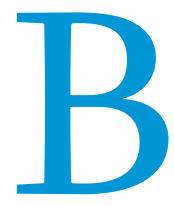

efore the semester began, I was notified that a student with a visual disability was enrolled in my research methods course. Although I have experience with providing disability accommodation in my classes, this would be the first time I taught a visually disabled student. I quickly discovered that portions of the course were inaccessible to this student and that I was unprepared to provide an equivalent learning experience. The principles of Universal Design in Instruction (UDI) provide guidance for developing curriculum that maximizes accessibility and usability of course content for all learners, including those with disabilities. This article examines the development of political science courses through the lens of UDI. During the semester, I made changes to the way I organized the class, delivered course content, and assessed student performance. These changes improved not only the accessibility of my course for students with visual disabilities but also my teaching in ways that benefited all students. Although the motivation for this article was my experience in a research methods course, the use of UDI is applicable in any class and across all disciplines.

\section{HOW STUDENTS WITH VISUAL DISABILITIES ACCESS COURSE MATERIALS}

To gain a better understanding of effective instruction and the accessible college classroom, a focus group of six undergraduate

Michael A. Taylor, is associate professor of political science and public affairs at Seton Hall University. He can be reached at michael.taylor@shu.edu. students with visual disabilities discussed (1) common technological barriers encountered in undergraduate courses, (2) effects of barriers on student performance, and (3) instructional strategies and methods used by professors that enhance learning. The group consisted of male and female students ranging from freshmen to seniors and representing five academic majors. The visual disabilities of the students included various forms of low vision (four students) and blindness (two students).

Low-cost, widely available software coupled with the digital delivery of course materials has expanded the accessibility of the written word. Digital text displayed on a screen can be converted to speech (i.e., screen readers), mechanically reproduced as braille characters on a specialized keyboard (i.e., refreshable braille display), and enlarged to an accessible size (i.e., screen magnifier). The choice of assistive technology combines personal preference, cost, and suitability, and these technologies are constantly improving and changing. Those discussed in this article were identified by the focus group, but they are not the only assistive technologies currently used by students with visual disabilities. Among the focus-group participants, three students read braille but none use it as a tool for accessing course materials. The blind students use text-to-speech screen readers (e.g., NonVisual Desktop Access [NVDA] and Job Access With Speech [JAWS]); those with low vision use a combination of text-magnification tools (e.g., ZoomText) and screen readers because prolonged use of the magnification tools alone is fatiguing.

In the classroom, the focus-group students use multiple tools for note taking. One low-vision student uses volunteer note takers; 
two students (i.e., one who is blind and one with low vision) use audio recorders; one low-vision student uses a combination of audio recorder and laptop; and two students (i.e., one who is blind and one with low vision) use only laptops. It is important to note that a student following along with prepared lecture materials (e.g., handouts and presentation slides) while also taking notes most likely is listening to the screen reader and instructor simultaneously as well as typing. As one student stated, "For some of us, we learn to take notes while listening to the reader. Sighted people get it easier than we do, but we developed skills that let us multitask better. Skill sets differ among [us]."

Students with visual disabilities encounter a recurrent set of problems with commonly used instructional technology. However, most of the problems can be resolved through minor changes in instructional practices that are completely within an instructor's control.

\section{UNIVERSAL DESIGN IN INSTRUCTION}

Research on pedagogical approaches for the use of instructional technology for students with visual disabilities includes Asuncion et al. (2004); Fuller, Bradley, and Healey (2004); Goodman, Tiene, and Luft (2002); and Wald, Draffan, and Seale (2009). Whereas numerous articles address specific STEM disciplines (Frasera and Maguvhe 2008; Jones et al. 2006; Singh 2008), little is available about the appropriate use in social and behavioral sciences. Assessment of the implementation of UDI principles in higher education is available from the perspective of students (McGuire and Scott 2006), faculty (Zhang et al. 2010), and the broader university community (Burgstahler and Cory 2008; Fichten et al. 2009).

Universal design is an engineering approach with the goal of making products, buildings, and environments usable by all content formatted in ways that limit use. Two federal statutes, the Americans with Disability Act (ADA) of 1990 and Section 504 of the Rehabilitation Act of 1973, require colleges and universities to ensure that students with disabilities are provided accessible course materials. If materials selected for the course do not meet the criteria, students contact the Disability Services Office (DSO) on campus, which is required to find accessible alternatives. This entails requesting accessible versions directly from the publisher or the instructor or scanning written materials into accessible versions. Reading materials in PDF format is a particular challenge. Providing course materials in this format is not sufficient to ensure accessibility; settings for PDF files are sensitive, and the files often are saved in a format that cannot be processed by screen readers. In addition, scans of weathered or annotated material can lead to difficulties with readers and magnifiers. Determining whether a PDF file is saved in an accessible format also can be a challenge. ${ }^{\text {Th }}$ The DSO works with faculty to ensure the accessibility of course materials, in advance, and can reformat files for use with screen readers and magnifiers if necessary.

Consideration of accessibility extends beyond course readings to include instructional tools that students are required to use. For example, many standard statistical software packages used in research methods courses (i.e., SPSS and Statistical Analysis System [SAS]) are not compatible with assistive technologies. The R software package, when used in terminal mode, is accessible and provides an equivalent experience compared to other statistical-analysis software (Godfrey 2013). Unfortunately, using R in terminal mode removes the simplicity of the graphical user interface that makes adoption of statistical software packages appealing.

An instructor must decide whether to (1) adopt $\mathrm{R}$ in terminal mode for all students, or (2) use it as an accommodation for students with visual disabilities and a graphical-user-interface-based

\section{The concept applied to higher-education curriculum as UDI (Scott, McGuire, and Shaw 2003) is a proactive approach to curriculum design and instructional strategies. It minimizes the need for accommodations and retrofitted fixes to existing instructional technologies and materials.}

people-to the greatest extent possible-without the need for any specialized adaptation or modification (Roberts et al. 2011). The concept applied to higher-education curriculum as UDI (Scott, McGuire, and Shaw 2003) is a proactive approach to curriculum design and instructional strategies. It minimizes the need for accommodations and retrofitted fixes to existing instructional technologies and materials. To highlight the ways that UDI can assist faculty in improving accessibility for those with visual disabilities, student comments from the focus group were mapped to the nine UDI principles. Appendix 1 summarizes these principles and provides suggestions for achieving them.

\section{Perceptible Information}

Ensure that readings and instructional materials are fully functional with commonly used accessibility tools (e.g., refreshable braille displays, screen readers, and screen magnifiers)

The most commonly mentioned barrier is nonaccessible course materials, including required readings and instructor-created platform (e.g., SPSS, SAS, Stata, and standard R) for other students. The first approach likely requires a major course redesign and adds an increased level of difficulty to the statistical-analysis portion of the course. The second approach requires the instructor to teach two different approaches in the same course. I continued to use SPSS with my class and converted assignments to $\mathrm{R}$ in terminal mode for the blind student. This solution was less than ideal because the student was isolated from the rest of the class. In the last four weeks of the semester, we met for weekly one-on-one sessions to replicate course material for use in R. The student expressed feelings of being ostracized, but it was the only way to ensure an equivalent statistical-analysis experience in that semester. ${ }^{2}$

\section{Size and Space for Approach and Use}

Recognize the diverse communication needs of students by incorporating multiple delivery methods

This principle is best summarized by a student who stated, "The more descriptive a faculty member can be in their lecture 
presentations, the better it is." Instructors often overlook the fact that images included in course materials cannot be processed by screen readers. This fails to recognize an important attribute of communication that has a significant impact on students with visual disabilities. Any image (e.g., a photograph, a drawing, and a graph) must be annotated to provide a description that can be read through the screen reader. In both Word and PowerPoint, this is accomplished by right-clicking on the image, selecting Format Picture, and then selecting Alt Text. The instructor gives the image a descriptive title and then explains the image in the text box. In class, the instructor should provide detailed descriptions of any image being presented. For example, reading aloud all labels and numbers in a table, each variable, and numbers and operators in an equation, as well as providing all relevant origin and data-point labels of a graph, may be required for full comprehension by students with visual disabilities.

Instructors also should provide digital versions of annotated images in advance of class, which allows students to use screen magnifiers or screen readers on their laptop to access the image information during the lecture. Otherwise, students with visual disabilities are unable to communicate and participate in the same manner as other students. If an electronic copy is not provided, the student must have the physical document scanned, which further delays access to the information. This can be a problem with activities such as "pop quizzes." If the instructor neglects to provide an electronic copy of the quiz before class begins, it is impossible for the student to complete the quiz in a timely manner. Simply administering the quiz by reading the questions aloud to all of the students, as opposed to printing the quiz, alleviates this problem without providing an accommodation. Considering the communication attributes that affect the transmission of instructional material to students is as important as the material itself.

\section{Equitable Use}

Ensure that instruction is accessible in formats that provide identical or, at a minimum, equivalent usage for students with different abilities

Although a digital textbook may be identical to the printed version, the supplemental materials often are not accessible. These materials include problem sets, interactive-learning modules, supplemental readings, and chapter summaries. Students in the focus group noted that alternatives provided by faculty are not always equivalent and often are of lower quality than the content created in synergy with the textbook.

Even more common than the textbook barrier, students mentioned that faculty reliance on visual-presentation tools (e.g., PowerPoint) to provide class lecture notes works poorly with screen readers and magnifiers. Whether the text is accessible or presented in the same order through assistive technology depends on file layout and formatting. Running the PowerPoint Accessibility Checker ensures compatibility. ${ }^{3}$ Word files are more reliable for use by students with visual disabilities, and providing course materials in both formats is an easy way to ensure access. ${ }^{4}$

\section{Flexibility in Use}

Vary instructional methods to allow students with diverse learning styles and abilities to demonstrate mastery

Providing accessible material ensures that students with visual disabilities consume the same content as other students.
However, the use of screen readers and screen magnifiers changes the way that a student interacts with the material. Two students in the focus group expressed frustration with classes that relied on traditional research papers and open-book exams as the primary-and, in one case, the only-assessment of student performance. As they noted, "Skim reading using a screen reader is not possible" and "...taking notes [while] modifying the document with the screen reader can cause bad crashes." The mechanics of completing tasks that require the search and reference of written texts is a difficult and time-consuming process. Nevertheless, open-book exams and traditional term papers should not be avoided. In fact, in many cases, they are the most appropriate assessment instrument for mastery of course objectives and goals. However, by using a combination of instruments within a course (e.g., oral presentations and group projects), an instructor may provide all students-especially those with disabilities-multiple ways to demonstrate competency.

\section{Tolerance for Error}

\section{Anticipate variation in individual student learning pace and adjust timing of assessment and feedback accordingly}

The most common accommodation given to students with visual disabilities is additional time to complete exams and assignments. Political science courses-research methods in particularoften require students to search for information using electronic databases. Although they are improving in terms of accessibility, many are not designed to work well with assistive technology. Even databases that meet the requirements provide search results that include a large percentage of inaccessible PDF files. Students with visual disabilities must choose between skipping the results or taking the time-consuming steps of downloading and rescanning them into an accessible format before they can assess whether an article fits their needs. The basic mechanics of using assistive technology to search and sort through the results provided by electronic databases is a frustratingly slow and difficult process. In my course, the time required for a blind student to satisfactorily complete the search-and-sort portion of the assignment equaled the time allotted for the entire assignment. To complete the full assignment, the student needed most of the semester rather than only the last six weeks. Another option was to have the assignment modified to reduce the search-and-sort portion.

It is important to provide flexibility in the timing of assignment submissions for students with visual disabilities. Breaking complex assignments into a several shorter components allows students to better manage their time. It ensures that they have the necessary time to complete all assignments, and it also provides the instructor with more opportunities to observe the students' learning progress and provide feedback.

\section{Simple and Intuitive}

Plan and deliver instruction in a straightforward and predictable manner that eliminates unnecessary complexity

A poorly planned and unorganized course negatively affects students with visual disabilities to a greater degree than other students. "The biggest problem is if the professor is not prepared to have me in class." If an instructor has not planned the course to be accessible to the student with visual disabilities before the semester begins, it is difficult to procure the required accommodations. 
"[If] a problem [with accessibility] comes up, and there isn't a plan for how to deal with it, you can end up a week or more behind," stated one of the focus-group members.

Posting course materials online in advance allows instructors and students to identify and address accessibility problems before they are encountered in class. Maintaining a content-rich and well-organized Learning Management System (LMS) course page is a simple way to achieve this. Most LMSs (i.e., Blackboard and Moodle) are compliant with current accessibility requirements of the Rehabilitation Act and the ADA (US Department of on the approach. The student recounted that one professor announced to the class, "Can anyone help [name redacted]? He needs somebody to give him notes." To avoid being singled out, the student would have preferred for the instructor to identify a potential note taker outside of classroom time.

Another student mentioned a subtle form of feeling singled out by faculty: "There is still this mentality, I guess, that maybe we don't know what is going on....I will be doing a group project and [the faculty member] will point out < whisper $>$ '[name redacted] is blind'.... It's like they treat you like a child.” There was agreement

A poorly planned and unorganized course negatively affects students with visual disabilities to a greater degree than other students. "The biggest problem is if the professor is not prepared to have me in class." If an instructor has not planned the course to be accessible to the student with visual disabilities before the semester begins, it is difficult to procure the required accommodations.

Education 2011). However, the accessibility of content placed in the LMS depends on the instructor. An example of unintentionally undermining this accessibility was referred to by a student as "The PDF Inception Problem." If a PDF version of the syllabus is posted with embedded links to PDF versions of readings, opening the files from within Blackboard often crashes the assistive technology, which then requires a system reboot. A simple and intuitive LMS layout in which content is provided through standalone links avoids these types of problems and makes finding information easier for all students.

\section{Low Physical Effort}

Provide coursework in ways that reduce the amount of nonessential effort

This principle encompasses both physical effort (e.g., standing for extended periods in a lab or classroom) and mental effort (e.g., studying amid distracting background noise). Nonessential physical or mental effort leads to fatigue and detracts from the learning experience. One technological source of nonessential mental fatigue mentioned by the focus group was the faculty requirement to use software and/or web services (e.g., Dropbox and Google Drive). Although these services, commonly used to facilitate group projects, are technically accessible using assistive technology, they are bug-prone and often lose connections, which results in lost data and continuous reboots. This does not necessarily prevent students from completing assignments; however, it causes them to expend more energy than necessary. As one student noted, "...use of specific programs should not be mandatory... [faculty] need to allow flexibility."

\section{Community of Learners}

\section{Foster interaction and communication among students}

The perception of peers is impacted by the way in which a faculty member interacts with a student who has a visual disability. One focus-group member requested a volunteer to share notes in each class as part of the student's accommodation. Although it is helpful for an instructor to assist in facilitating this request, it also can be an "awkward" and "embarrassing" experience, depending that whereas they felt that instructors are attempting to be helpful, it often results in the student feeling ostracized from the class.

One student suggested being more proactive to ensure that others are aware that "visual disability doesn't limit our ability to understand." For example, "Show the professor you are like the rest of the class by participating...be aggressive...raise your hand...make the professor tell you they want to hear from others." The student reasoned that it "...helps when you have a group project because other students know that you know your stuff... [and will] want you in their group.... [It] might be different otherwise."

\section{Instructional Climate}

Promote an atmosphere that shows a willingness to meet the instructional needs of all students and encourages students to convey their needs

According to students in the focus group, the instructional climate of the classroom is largely determined by the willingness of an instructor to openly communicate and engage with a student about expectations and plans for accomplishing course goals. The ADA and the Rehabilitation Act require that accommodations be provided only to students with documented, qualifying disabilities. Formal notification typically is provided to faculty through a letter from the DSO on or before the first day of class. The letter provides details regarding the qualifying disability and offers suggested accommodations. It should be perceived as the starting point of a discussion on how best to meet the needs of the student while also maintaining academic expectations. "It is not unusual for instructors to be unaware of the needs of students with disabilities or to perceive academic adjustments for these students (such as extended time or note takers) as negatively affecting the academic integrity of the assignment or of the course... [and] may be viewed as an 'unfair advantage' to a student" (US Department of Education 2011). Disabilities are not necessarily openly discussed by faculty and students, which can negatively affect the experience of both parties. A student in the focus group noted that there are benefits to an honest conversation with instructors, even when they are not 
interested in providing any accommodation. "It is better off for both of us; the professor can teach it the way he wants and I can drop the class and take it with someone else." Faculty should be open to these discussions when the need arises. It is always important to communicate with students; however, the more technologically rich the course, the more important it is to make contingency plans for accommodation if accessibility problems arise. It is critical to have this conversation early in the course to ensure that the class maintains the required rigor for all students.

\section{CONCLUSION}

Faculty need to take responsibility for both the technology that they choose to use and that which they choose not to use. Both decisions can have a significant impact on student accessibility. Research methods courses and the technology relied on (e.g., statistical packages and online databases) pose specific problems for students with visual disabilities. Instructors should design their courses with UDI principles in mind because they promote accessibility for students with disabilities as well as improve the course quality for all students.

\section{ACKNOWLEDGMENTS}

This work was supported in part by the Center for Mobile Research and Innovation at Seton Hall University. I thank the students who participated in the focus group; Angela Millman, Director of the Seton Hall University Office of Disability Support Services; and my graduate assistant, Carley Lesinski, for their assistance with this project. This article benefited from the comments of multiple reviewers, including participants in the Research Methods Track at the 2015 APSA Teaching and Learning Conference. In particular, Cameron Thies and Bill Wilkerson helped to shape the earliest version of this manuscript. Any remaining errors or omissions are those of the author alone.

\section{NOTES}

1. The Accessibility Wizard in Adobe Acrobat Pro can be used to check file accessibility. A good primer on creating accessible PDF files and accessibility settings in Adobe Acrobat is available at http://webaim.org/techniques/acrobat/ convertinghttp://webaim.org/techniques/acrobat/converting.

2. Changing the entire class to the $\mathrm{R}$ software package is appealing because it is a powerful, free, open-source statistical package with a vibrant community that supports its continued development. Students who learn using R can continue to use the package for classes throughout their undergraduate years and beyond the course. There are good political science data-analysis books that use the R software package. The choice of statistical software package may be limited to research methods courses within political science. However, this discussion about the impact of accessibility of any required software packagesand the impact of that choice on all students in the course-is applicable to any technology-infused course.

3. Instructions for using the Microsoft Accessibility Checker for Word and PowerPoint files are available at https://support.office.com/en-us/article/ Check-for-accessibility-issues-a16f6deo-2f39-4a2b-8bd8-5ad8o1426c7f?ui=enUS \& rs=en-US\&ad=UShttps://support.office.com/en-us/article/
Check-for-accessibility-issues-a16f6deo-2f39-4a2b-8bd8-5ad8o1426c7f?ui=enUS\&rs=en-US\&ad=US.

4. The steps for converting PowerPoint files into Word files are available at www.udemy.com/blog/convert-powerpoint-to-word.

5. This is a modified version of a table presented in the UDI Online Project (2009).

\section{REFERENCES}

Asuncion, Jennison V., Catherine S. Fichten, Maria Barile, Myrtis E. Fossey, and Chantal Robillard. 2004. "Access to Information and Instructional Technologies in Higher Education II: Practical Recommendations for Disability Service Providers." Journal of Postsecondary Education and Disability 17 (2): 134-7.

Burgstahler, Sheryl E., and Rebecca C. Cory, eds. 20o8. Universal Design in Higher Education: From Policy to Practice. Cambridge, MA: Harvard Education Press.

Fichten, Catherine S., Vittoria Ferraro, Jennison V. Asuncion, Caroline Chwojka, Maria Barile, Mai N. Nguyen, et al. 2009. "Disabilities and e-Learning Problems and Solutions: An Exploratory Study." Journal of Educational Technology and Society $12(4): 241-56$.

Frasera, William John, and Mbulaheni Obert Maguvhe. 2008. "Teaching Life Sciences to Blind and Visually Impaired Learners." Journal of Biological Education 42 (2): 84-9.

Fuller, Mary, Andrew Bradley, and Mick Healey. 2004. "Incorporating Disabled Students within an Inclusive Higher Education Environment." Disability and Society 19 (5): 455-68.

Godfrey, A. Jeffrey R. 2013. "Statistical Software from a Blind Person's Perspective." The R Journal 5: 73-9.

Goodman, Glenn, Drew Tiene, and Pamela Luft. 2002. "Adoption of Assistive Technology for Computer Access among College Students with Disabilities." Disability and Rehabilitation 24 (1-3): 80-92.

Jones, M. Gail, James Minogue, Tom Oppewal, Michelle P. Cook, and Bethany Broadwell. 2006. "Visualizing without Vision at the Microscale: Students with Visual Impairments Explore Cells with Touch.” Journal of Science Education and Technology 15 (5-6): 345-51.

McGuire, Joan, and Sally Scott. 2006. "An Approach for Inclusive College Teaching Universal Design for Instruction." Learning Disabilities: A Multidisciplinary Journal 14 (1): 21-31.

Roberts, Kelly D., Hye Jin Park, Steven Brown, and Bryan Cook. 2011. "Universal Design for Instruction in Postsecondary Education: A Systematic Review of Empirically Based Articles." Journal of Postsecondary Education and Disability 24: $5-15$.

Scott, Sally S., Joan F. McGuire, and Stan F. Shaw. 2003. "Universal Design of Instruction: A New Paradigm for Adult Instruction in Postsecondary Education." Remedial and Special Education 24: 369-79.

Singh, M. 2008. "Visionmeter: A Novel Instrument for Teaching Chemical Sciences to the Visually Handicapped." Experimental Techniques 32 (2): 53-7.

UDI Online Project. 2009. "Examples of UDI in Online and Blended Courses." Center on Postsecondary Education and Disability. Storrs: University of Connecticut. Available at http://udi.uconn.edu/index.php?q=content/examples-udionline-and-blended-courses. Accessed on November 20, 2014.

US Department of Education. 2011. Advisory Committee on Accessible Instructional Materials in Postsecondary Education for Students with Disabilities. Available at www2.ed.gov/about/bdscomm/list/aim/publications.html. Accessed on November 20, 2014.

Wald, Mike, E. A. Draffan, and Jane Seale. 2009. "Disabled Learners' Experiences of e-Learning." Journal of Educational Multimedia and Hypermedia $18(3): 341$.

Zhang, Dalun, Leena Landmark, Anne Reber, HsienYuan Hsu, Oi-man Kwok, and Michael Benz. 2010. "University Faculty Knowledge, Beliefs, and Practices in Providing Reasonable Accommodations to Students with Disabilities." Remedial and Special Education 31 (July/August): 276-86. 


\begin{tabular}{|c|c|c|}
\hline Nine Principles of UDI & $\begin{array}{l}\text { Definition as Applied to Students } \\
\text { with Visual Disabilities }\end{array}$ & Examples of Potential Actions \\
\hline \multirow[t]{2}{*}{ 1. Equitable Use } & \multirow{2}{*}{$\begin{array}{l}\text { Ensure that instruction is accessible in } \\
\text { formats that provide identical or, at } \\
\text { a minimum, equivalent usage for students } \\
\text { with different abilities. }\end{array}$} & $\begin{array}{l}\text { - Be aware that whereas the provision of identical accessible } \\
\text { versions of textbooks is becoming more commonplace, } \\
\text { the ancillary study materials often are not. }\end{array}$ \\
\hline & & $\begin{array}{l}\text { - Use built-in accessibility-checking features in Word and } \\
\text { PowerPoint. }\end{array}$ \\
\hline 2. Flexibility in Use & $\begin{array}{l}\text { Vary instructional methods to allow } \\
\text { students with diverse learning styles and } \\
\text { abilities to demonstrate mastery. }\end{array}$ & $\begin{array}{l}\text { - Assess student competency and understanding using } \\
\text { a combination of instruments that provide multiple means } \\
\text { of expression (e.g., essay exams, oral reports, and reflective } \\
\text { writing). }\end{array}$ \\
\hline \multirow[t]{3}{*}{ 3. Simple and Intuitive } & \multirow{3}{*}{$\begin{array}{l}\text { Plan and deliver instruction in } \\
\text { a straightforward and predictable manner } \\
\text { that eliminates unnecessary complexity. }\end{array}$} & - Provide course information and content in advance of use. \\
\hline & & $\begin{array}{l}\text { - Use logical and simplified layouts for content in Learning } \\
\text { Management Systems. }\end{array}$ \\
\hline & & - Design lectures to follow a clear outline with specific goals. \\
\hline \multirow[t]{2}{*}{ 4. Perceptible Information } & \multirow{2}{*}{$\begin{array}{l}\text { Ensure that readings and instructional } \\
\text { materials are fully functional with } \\
\text { commonly used accessibility tools } \\
\text { (e.g., refreshable braille displays, screen } \\
\text { readers, and screen magnifiers). }\end{array}$} & $\begin{array}{l}\text { - Be aware that not all PDF files are compatible with assistive } \\
\text { technologies. }\end{array}$ \\
\hline & & $\begin{array}{l}\text { - Perform due diligence on any specialized software that } \\
\text { students are required to use as part of the course. }\end{array}$ \\
\hline 5. Tolerance for Error & $\begin{array}{l}\text { Anticipate variation in individual student } \\
\text { learning pace and adjust timing of } \\
\text { assessment and feedback accordingly. }\end{array}$ & $\begin{array}{l}\text { - Break complex assignments into smaller components to } \\
\text { provide more feedback, and plan for the possible need for } \\
\text { extended time. }\end{array}$ \\
\hline \multirow[t]{2}{*}{ 6. Low Physical Effort } & \multirow[t]{2}{*}{$\begin{array}{l}\text { Provide coursework in ways that reduce } \\
\text { the amount of nonessential effort. }\end{array}$} & $\begin{array}{l}\text { - Avoid technology that, although accessible, is difficult to use } \\
\text { with assistive technologies. }\end{array}$ \\
\hline & & $\begin{array}{l}\text { - Allow students flexibility in the choice of software and } \\
\text { services used in the course. }\end{array}$ \\
\hline \multirow[t]{2}{*}{ 7. Size and Space for Approach and Use } & \multirow{2}{*}{$\begin{array}{l}\text { Recognize the diversity of ways that } \\
\text { students communicate and interact in } \\
\text { the classroom, and meet their needs } \\
\text { through multiple delivery methods. }\end{array}$} & $\begin{array}{l}\text { - Use image tags to provide descriptions of charts, tables, } \\
\text { and graphics used in class materials. }\end{array}$ \\
\hline & & $\begin{array}{l}\text {-When using images in lectures, ensure that full descriptions } \\
\text { of all elements are provided as part of the delivery. }\end{array}$ \\
\hline 8. Community of Learners & $\begin{array}{l}\text { Foster interaction and communication } \\
\text { among students. }\end{array}$ & $\begin{array}{l}\text {-While ensuring an accessible learning experience, be aware of } \\
\text { communication signals that might be perceived by students } \\
\text { in the class. }\end{array}$ \\
\hline 9. Instructional Climate & $\begin{array}{l}\text { Promote an atmosphere that shows } \\
\text { a willingness to meet the instructional } \\
\text { needs of all students and encourages } \\
\text { students to convey their needs. }\end{array}$ & $\begin{array}{l}\text { - From the outset, engage with students about accommodations } \\
\text { and course expectations. }\end{array}$ \\
\hline
\end{tabular}

